\title{
Esferocitosis Familiar Congénita
}

\author{
Drs.: Roberto Figueroa S. 1, Mario Rivera G. 1.2, \\ T.M.: Sras.: Egele Tamburrino C. ${ }^{1}$, Margarita Moroso B. ${ }^{1}$
}

\section{Congenital Sphenocytosis}

\begin{abstract}
Four cases in a lanily affected with hereditary spherocy tosis are analized. One of them suffered an hipoplastic episode during the study.
\end{abstract}

El estudio de un caso de Esferocitosis Familiar Congènita en el Servicio de Pediatría de nuestro Hospital permitió pesquisar tres miembros afecta. dos en su grupo familiar, siendo estos, los primeros pacientes de esta patología diagnosticados en la ciudad de Vallenar. Esto nos motivó a revisar la literatura y comunicar nuestra experiencia.

En el estudio de estos pacientes se utilizó hemograma fragilidad osmótica, test de Coombs y revision de los antecedentes clínicos.

\section{Casos Clínicos}

G.C.M. Mujer 14 affos de edad, caso indice de nuestra publicación, ingresa al Servicio de Pediatría del Hospital de Vallenar en Junio de 1982 portando un cuadro de Infección del tracto urinario a E. coli, destacaba además al examen físico una marcada palidez de piel y mucosas, coloración amarilla de escleras y esplenomegalia moderada.

El hemograma al ingreso mostró un Hto. $=14 \%$. Hb 5,9 gr. \%, reticulocitos: $40,5 \%$. Al frotis se apreció anisocitosis $^{++}$microesferocitosis ${ }^{+++}$policromatofilia ${ }^{*}$ anisocromía ${ }^{*+}$. Prueba de Coombs negativa, Bilirrubinemia total $=4,6 \mathrm{mg} \%$ de predominio indirecto. El test de fragilidad osmótica no se pudo realizar inicialmente por no estar montada la técnica en esta ciudat.

El análisis de su anamnesis remota personal

\footnotetext{
1 Hospital Vallenar.

2 Trabajo ingreso a la Sociedad Chilena de Pediatría.
}

reveló una hospitalización a los tres años de edad por un cuadro de anemia severa con cifras de Hto. $=7 \%, \mathrm{Hb}=2,7 \mathrm{~g}, 100 \mathrm{ml}$ siendo transfundida sin llegar a un diagnóstico etiológico.

Con todos estos antecedentes se planteó el diagnóstico de hemolítica, fue transfundida y se inició el estudio de su grupo familiar.

P.C.M. Varón de 13 afios, (hermano) con el antecedente de hospitalización a los 2 años de edad por un cuadro de anemia severa con cifras de Hto $=20 \%, \mathrm{Hb}=6.5 \mathrm{~g} / 100 \mathrm{ml}$, se transfundió $\mathrm{y}$ fue dado de alta sin diagnóstico etiológico.

Al examen clínico actual se encontró palidez de piel y mucosas y moderada esplenomegalia.

El Hemograma demostró Hto $=29 \%, \mathrm{Hb}=10,1$ g/ $100 \mathrm{ml}$., reticulocitos $20 \%$. Al frotis sanguineo: anisocitosis ${ }^{++}$, microcitosis ${ }^{++}$, microesferocitosis ${ }^{+}$, policromatofilia $^{*+}$, anisocromia ${ }^{*}$. Prueba de Coombs negativa, fragilidad osmótjca aumentada.

C.C.M., Niña de 10 años de edad (hermana), sin antecedentes mórbidos. El examen físico actual no revela alteraciones, sin embargo al laboratorio presenta un test de fragilidad osmótica aumentada y un hemograma con Hto $=34 \%, \mathrm{Hb} 12,1 \mathrm{~g} / 100$ nll. Al frotis existe anisocitosis ${ }^{++}$, microcitosis ${ }^{++}$, microesferocitosis ${ }^{*}$, policromatofilia ${ }^{*}$. Prueba de Coombs negativa. Durante la investigación clínica se hospitaliza por presentar una crisis hipoplástica. Al hemograma: $\mathrm{Hto}=12 \%, \mathrm{Hb}=5,3 \mathrm{~g} / 100 \mathrm{ml}$., reticulocitos $0,2 \%$; en el frotis existe anisocitosis $^{++++}$, microesferocitosis ${ }^{+++}$anisocromía ${ }^{+++}$. 
N.M.T., Mujer de 38 años (madre). En su anamnesis remota personal existe una hospitalización a la edad de 26 años por un cuadro anémico con cifras de Hto de $11 \%$, Bilimrubinemia 0,95 $\mathrm{mg} \%$, y esplenomegalia se transfunde y es dada de alta sir. sgnóstico etiológico.

Al examen clínico actual destaca palidez de piel y mucosa con leve esplenomegalia. El estudio de laboratorio muestra, hemograma: Hto $34 \%, \mathrm{Hb}$ $11,8 \mathrm{~g} / 100 \mathrm{ml}$, reticulocitos $17,4 \%$; al frotis: anisocitosis $^{+++}$microcitosis ${ }^{+++}$, microesferocitosis $^{++}$, policromatofilia ${ }^{++}$, anisocromía ${ }^{+}$.

Bilirrubinemia total $3,4 \mathrm{mg} \%$ de predominio indirecto. Prueba de Coombs negativa, fragilidad osmótica aumentada.

Una vez concluida la exhaustiva confección de la anamnesis remota familiar $y$, a la luz de los hallazgos de taboratorio en que el hemograma nos indica la existencia de una anemia hemolítica familiar de tipo esferocítico; se debe montar la técnica de fragilidad osmótica recurso con que no contábamos en ese momento y que nos permitió establecer el diagnóstico motivo de la publicación de este trabajo. Tabla 1.

Tabla 1.

Cuadro genealógico đe la familia afectada(*)

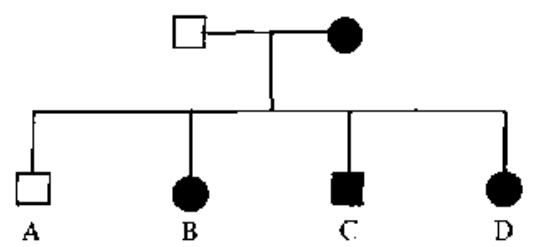

Afectado.

Madte N.M.T, 38 años.

A. Varón, H.C.M. 16 años.

B. Niña, caso índice G.C.M. 14 afios.

C. Varón, P.C.M. 13 años.

D. Niña, C.C.M. 10 años.

(*) (No existen antecesores vivos, ambos padres hijos unicos).

\section{COMENTARIO}

La esferocitosis familiar congénita, es una anemia hemolitica, de causa genética, que cursa con tasa elevada de destrucción erítrocitaria, esferocitos en sangre, aumento de fragilidad osmótica globular, esplenomegalia y, remisión de la sintomatología hemolítica con la esplenectomial-2-3-4

Se transmite en forma autosómica dominante, con penetración $y / o$ expresión incompleta, con mutaciones espontáneas transmitidas en forma recesiva, dando lugar a cuadros de severidad variable en distintos miembros de una misma familia ${ }^{1-4 \cdot 5-6-7}$.

Al parecer existiría relación entre la herencia de esta enfermedad y el sistema $\mathrm{HLA}^{8-9}$ lo que estatía en discusión ${ }^{6}$.

Es la anemia hemolitica más frecuente, con una incidencia estimada de 1 a 2 casos de cada 15.000 habitantes ${ }^{1 \cdot 4 \cdot 5}$.

La primera descripción de este padecimiento data de 1871, fecha en que Vanlaer y Masius ${ }^{7-10}$ la denominaron microcitemia. Posteriormente en 1900, Minkowsky 10-1 1 hace una detallada relación de hallazgos en esta enfermedad y es sin embargo, Chauffard 10-12 quien en 1907, marca hitos importantísimos al darle dimensión hematológica a esta afección, y no hepática como hasta aquella fecha se la había considerado; describe la alteración de la fragilidad osmótica globular y, va más lejos al afirmar que, esta fragilidad es congénita, hereditaria y familiar en este mal ${ }^{12}$.

Desde aquelia época hasta nuestros dias, se ha investigado en múltiples direcciones tratando de aportar nuevas luces a la etiopatogenia de la enfermedàd, concentrándose estos estudios en la membrana del esferocito. Podemos reseñar las alteraciones descritas en el glóbulo rojo afectado, como sigue:

Aumento de permeabilidad de la membrana al $\mathrm{Na}^{+}$(hacia el interior de la célula), lo que redunda en una mayor probabilidad del eritrocito de adquirir la forma esférica ${ }^{\text {1-2-3-4-1 3-14. }}$

Aumento del $\mathrm{Ca}^{++}$Intracelular, el que tiene la propiedad, dentro del esferocito, de inhibir la fosforilización de polipéptidos de membrana; de producir rigidez de la membrana lo que explica su mayor facilidad de hemólisis ${ }^{1-14}$.

EI esferocito posee una mayor actividad glicolítica, con elevado consumo de ATP, aumentando el riesgo de hemólisis frente a condiciones de deprivación metabólica ${ }^{1-13}$.

Disminución, alteración en la organización, o franca anormalidad de los componentes lipídicos de la membrana, conllevando al esferocito a perder lípidos de su membrana a tasa mayor que to normal en situaciones de stress metabólico ${ }^{3-13-15-16}$.

Disminución de fluidez de membrana, lo cual implica, que el esferocito al tener rigidez mayor que lo normal, ésta impediría su deformación fisio. 
lógica al pasar por capilares sanguíneos de menor djámetro que éll 3-17-19 hallazgo controvertido por Cooper ${ }^{15}$.

Deficiencia estructural o funcional de la espectrina-proteína responsable de la forma bicóncava del eritrocito $y$, que es a la vez el principal sustrato de una proteinkinasa de membrana, situación que a juicio de los investigadores es lo mas importante en esta enfermedad 13-14-16-17. $19 \cdot 20 \cdot 21 \cdot 22-23$.

Alteraciones de la fosforilización de la membrana, especialmente en el transporte de algunos

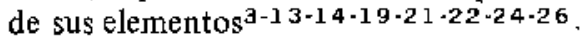

La simple suma de las alteraciones bioquímicas $y / 0$ estructurales en el esferocito hace, que los pacientes que padecen esta enfermedad, posean eritrocitos con menor capacidad de deformación fisiológica que los eritrocitos de individuos normales 3-17 y, a la vez, mayor facilidad de hemólisis frente a situaciones de poca disponibilidad de nutrientes ${ }^{1-13-14}$

El eritrocito normal ( $7 u$ ) es deformable y capaz de elongarse losuficiente como para atravesar las fenestraciones en los sinusoides esplénicos (3u).

El esferocito, en cambio, es extremadamente rígido para traspasar la microcirculación esplénica, traduciéndose en un enlentecimiento de la circulación en este órgano y, como consecuencia de ello e) esferocito es fagocitado por las células retículo endoteliales del bazo. Aquellos esferocitos que salvaron de su destrucción esplénica, la permanencia en aquel sitio les significó pérdida de trozos de membrana (por el $\mathrm{pH}$ ácido, baja disponibilidad de glucosa) y son destruidos en los tránsitos posteriores por el bazo. El bazo, por lo tanto, destruye los esferocitos rígidos $\mathrm{y}$, posee un medio ambiente que acelera la destrucción esferocitica ${ }^{1-4-5-17}$.

La presentación clínica de los pacientes varía de acuerdo a la edad y severidad de la hemólisis: siendo lo más frecuente los signos y sintomas atribuibles a esta destrucción eritrocítica aumenta. $\mathrm{da}^{1-4-5}$.

Frecuentemente existe en la anamnesis familiar antecedentes de: Anemia, ictericia, esplenomegalia, esplenectomía, colelítiasis ${ }^{4-5}$. Sin embargo, en alrededor de] $25 \%$ de los casos los antecedentes familiares no existen, dificultando de sohremanera el diagnóstico preciso ${ }^{1-2 \cdot 4-5-7-27}$.

La anemia es de grado variable, con signos hematológicos secundarios a la elevada tasa de lisis globular ${ }^{1-4-5}$.

La Prueba de fragilidad osmótica incubada, es uno de los más útiles ${ }^{1-2-5-27}$ con una sensibilidad de alrededor $85 \%$ 5-27-28. Las de fragilidad osmótica sin incubación tienen una sensibilidad cercana al $80 \% 27-28$.

Ultimamente se han introducido algunas técnicas que mejoran la sensibilidad y la especificidad como ser: Prueba de lisis por glicerol acidificado (AGLT) y, el transporte de fosfoenolpiruvato a través de mernbrana (PEPT) ${ }^{3-27-28}$. Ambos necesitan de gran infraestructura para su implementación, lo que limita su ejecución sólo a escasos centros mundiales đe investigación ${ }^{27-28}$.

Otras anemias hemoliticias esferocíticas son:

- Anemias inmunohemolíticas; en ellas las pruebas de Coombs directa, indirecta, o ambas, son positivas en la mayoría de los casos ${ }^{5}$.

- Anemias 2 años a la acción de oxidantes sobre glóbulos rojos con alteraciones previas como deficiencia de glucosa 6 Fosfato Deshimdrogenasa, hemoglobinopatías inestables, etc:; tales pacientes poseen cuerpos de Heinz ${ }^{5}$.

- Anemias provocadas por agentes físicos, como por ejemplo la exposición a las altas temperaturas $5^{5}$.

- Toxinas: Anemias secundarias a los efecros de Clostridium, arañas, serpientes, abejas, avispas; en todas ellas existe el antecedente respectivo ${ }^{5}$.

Anemias originadas en otras causas en las que la existencia de estigmas caracteristicas aclarará el diagnóstico como por ejemplo la Enfermedad de Wilson 5

Complicaciones:

-- Enfermedad hemolitica del recién nacido; debido a la gran hemólisis, necesita vigilancia estrecha del nivel de bilitrubina, pues no pocas veces se ha requerido inclușo de exsanguíneotransfusión 1-15.

- Episodios hipoplasticos transitorios; como su nombre lo indica, son de resolución espontánea $y$, duran entre 7 y 10 días. Se presentan siguiendo, habirualmente a una infección viral. Se presume que el agente infeccioso pudiera producir un daño citolítico directo o inmunológico a la médula ósea, comprometiendo a los precursores de la serie roja exclusivamente (crisis eritro. blastopénicas) o todas las otras series en menor o mayor medida (hipoplasia, aplasia respecti. vamente) $)^{1-5-29}$.

- Deficiencia de ácido fólico. El ácido fólico es fundamentai para la adecuada eritropoiesis, y 
como ésta se encuentra acelerada, hay mayor requerimiento, el que no logra ser cubierto con el aporte dietético diarjo ${ }^{1-5}$

- Colelitiasis, debido a hemólisis exagerada y al nivel aumentado de bilirnbina en el circuito enterohepático 4-5-30-31.

Durante los episodios hipoplásticos transitorios, es menester vigilar el estado hemodinámico del paciente $\mathrm{y}$, aportar glóbulos rojos por transfusión $y$ ácido fólico ${ }^{1-5}$. La transfusión es indispensable por otra parte, para compensar los episodios neurolíticos muy severos.

Como la presencia del bazo es esencial para que el defecto de membrana se manifieste en forma de proceso hemolitico, la esplenectomía resulta ser el tratamiento de elección ${ }^{1-2 \cdot 4-5}$.

La esplenectomía se debe efectuar en lo posible después de los 5 años de edad, para disminuir el riesgo de adquirir infecciones graves en los pacientes esplenectomizados, las más frecuentes de las cuales son las infecciones meningo encefálicas y las septicemias por Streptococo pneumoniae $y$ Hemophilus inf]uenza. Para minimizar este peligro se recomienda usar vacuna antineumocócica antes de la esplenectomia y hacer profilaxis con Penicilina. Debe informarse a los padres de la necesidad de consultar precozmente cuando aparezca fiebre en todo paciente con esplenectomia ${ }^{1 \cdot 4-5}$.

Lna vez efectuada la espienectomía, la sobrevida de los esferocitos está alargada pero, sin alcanzar la vida media normal, reduciendo los episodios de hipoplasia transitoria, deficiencia de ácido fólico, y posibilidad de consolidar una colelitiasis. Pudiera haber ocasiones en que se presenten procesos hemolíticos post esplenectomía, explicados sobre la base de existencia de bazos accesorios no extirpados en el momento de efectuarse la exéresis del órgano.

La esferocitosis familiar congénita es una enfermedad heterogénea y esta heterogeneidad se tradu. cría en la disímil presentación clínica en distintos miembros de familias afectadas $y$, los hallazgos diversos de las diferentes investigaciones ${ }^{2 \cdot 6 \cdot 7 \cdot 13}$. $15-16$

La familia de nuestra paciente se ajusta a la descripción clásica de la herencia de la enfermedad, como queda aclarado en la Tabla 1.

Al tiempo de la presentación de este trabajo, los 3 pacientes en edad pediátrica de nuestra familia fueron derivados al Hospital "Roberto del Rio", donde se comprobó el diagnóstico:

- G.C.M. fue esplenectomizada en Junio de 1982, encontrándose un bazo de 800 gramos y además, como hallazgo operatorio colelitiasis, que se deja para una segunda intervención. Actualmente se encuentra en buenas condiciones. Recibió vacuna antineumocócica antes de la esplenectomía.

- C.C.M. y P.C.M. se esplenectomizan en Noviembre de 1982 evolucionando satisfactoriamente; se descartó colelitiasis, previa a la intervención, mediante ecografia y recibieron vacuna antineumocócica, actualmente en excelentes condiciones de salud.

La crisis hipoplástica que presentó C.C.M. en el transcurso del estudio constituye una de las complicaciones con que evoluciona ta esferocitosis familiar congénita.

El diagnóstico diferencial con la crisis hemolítica se fundamenta en la disminución número de reticulocitos, como ocurrió en este caso en la ausencia de evidencias clínicas y de laboratorio de hemólisis. El proceso es usualmente autolimitado, pero el paciente debe observarse hasta el retorno de la reticulocitosis.

Queremos hacer hincapié en la importancia que tienen, tánto el análisis clínico como el Hemograma como elementos orientadores para el estudio de la Anemia Hemolítica, como queda demostrado en los casos presentados.

\section{REFERENCIAS}

${ }^{3}$ Rencoret G., y col.: Esferocitosis hereditilia. Bol. Hüsp. Saln Juan de Dios 26: 293, 1979.

- Fukagowa N., y col: Hereditary spherocy tosis with tormal osmotic fragility after incubation. Is the autohemolysis test really obsolete?. JAMA 242: 63, 1979.

Ideguchi H., y col.: Abnormal phosphocnolpytuvate transport in erythrocytes of hereditary spherocytosis. Blood 58: 426, 1981

"Rutkow In., y col.: Twenty years of splenectomy for hefeditary spherocy tosis. Arch. Surg. 116:306, 1981.

5 Sullitan Dw. y col.: Hereditary splierocy tosis. Pediatr. Ann. 9: 308, 1980 .

6erniks/f-Etievant MF., y col.: Hereditary spherocytosis linkage. Be. J. Haematol. 46: 153, 1980.

${ }^{7}$ Stevens $R F ., y$ col.: Congenital spherocy tosis is olten not hereditary. Clin. Pediatr. (Philaj 20: 47, 1981.

b Kimberling WJ, fr col.: Linkage and gene localization of hereditary spherocytosis (HS). Blood 52: 859, 1978.

9 Sengar DPS, y col.: HLA and hereditary spherocy. tosit. Vox Sanguinis 33: 278, 1977 .

10 Bené $J L$.: Histoire de la sphérocy tose congénital: Nour, Rev. Fr. Hematol. 23: 177, 198]

11 Minkowsky $M_{\text {.: }}$ Ucber cine hereditäre, unter dem bilde cines chronischen icterus mit u robilinuric, splenomegalie und nierensiderosis verlaufende affection. Semaine Med.: 149. 1900.

12 Chauffard MA.: Pathogénie da l'ictóre congenital do l'adulte. Semaine Med. I6 Javier 1907.

13 Mazo $E$, y col.: Estudio de la composición proteica do la membrana eritrocitaria en esferocitosis hereditaría. Sanyre (Barc) 24: 376, 1979 .

14 Nakao M., y col.: Membrane protein phosphorylation in intact nosmal and hetcditary spherocytic humas erythrocytes. J. Biochem (Tokyo) 88: $327,1980$. 
15 Cooper RA, $y$ col.: Normal fluidity of red cells membranes in hercditary spherocytosis: a spin label study. Br. J. Haematol. 46: 299, 1980.

16 Lung $L W$., y col.: Detection of erythrocyte mimbrane protein alterations in hereditary spherocy tosis through the use of thermal stress: a spin label study. Life Sci. 29: 207, 1981.

17 Devoge $M ., y$ col.: Study of spcetun plosphorylation and polymerization in nommal and spherocytic red blood celts (proceedings). Arch. int. Phy siol. Biochem. 87: 805, 1979.

is Jansson $S E$, y col:: The fluidity gradient in erythrocy. tes membranes in hereditary spherocytosis: a spin label study. Br. J. Hacmatol. 46: 73, 1980.

19 Thompwon S, , $y$ col:: The ubnomal phosplorylation of spectrin in luman hercditary spherocytosis. Bicchum Biophys Act a 649: 31, 1981 .

20 Lit $S C$, y col. Altercd spectrin dimer-dinuer association and instability of erythrocy te membrane skeletons in hexeditary py ropoikilocy tosis. J. Clin. Invest. 68: 597,1981 .

21 Thompront S., $y$ col.: The molecular basis of the defect iл phosphorylation of spectrin in human hereditary spherocytosis. Biochim. Biophys Acta 649: 38, 1981.

22 Tsung ${ }^{2}$., $y$ cot.: Red cell membrane protein phosphorylation in hemolitic anemias and muscular dystrophies. Muscle Netve 3: 55, 1980.

${ }^{23}$ Lux $S E$., y col.: Hemolytic anemias associated with deficient or dysfunctional spectrin. Prog. Clin. Biol. Res. 30: 463, 1979.

24 Ideguchi H., y col:- Abnormal phosphoenolpyruvate transport in erythrocytes of hercditary spherocytosis. Acta Biol. Med. Ger. 40: 555, 1981.

25 Yawata $Y$., y col.: Mcmbranc protein phosphorylation and protein kinases in nomal and hereditary spherocytosis red cells. Hemoglobin 4: 717, 1980.

${ }^{26}$ Boivin P., $y$ col: Altered erythrocyte membrano protein phosphorylation in an unusual casc of here. ditary spherocytosis Scand J. Haemafol, 23: 251, 1979 .

27 Zanella A., y col: Acidified glycerol lysis test: a screening test for spherucytosis. Br. J. Haematol. 45: 481,1980 .

28 Zanetha A., y col:: Screcning tests for spherocytosis. Br. J. Haematol. 49: 489, 1981.

29 Masera $G_{*}, y$ col.: Transient aplastic erisis in hereditary spherocy tosis. Atta Haematol. (Basel) 63: 28, 1980 .

30 Levitt RE., y col.: Hemoly tic jaundice and gallstones. Gastroenterology 78: 821, 1980.

31 Pignal N., y col:: Obstructive jaundice and cholelithjasis revealing Minkowsky .Chauffard's disease in a child younger than 3 years. Pediatrie 33: 795, 1978.

${ }^{32}$ Kies $\boldsymbol{M S}$, y cot.: Recutrence of hemolysis in hereditary spherocytosis: a case due to leukenic infiltarion of an accessory splecn. Milit. Med. 146: 55, 1981. 